\title{
LIVER TRANSPLANTATION: COMPLICATIONS AND TRANSFUSION. COMPARATIVE STUDY BETWEEN BRAIN DEATH AND TYPE III MAASTRICHT DONORS
}

\author{
Suárez del Arco, JA; Simic, D; Peral, A. I; Serrano, C. Abdallah N. A; Piñero M. \\ Hospital Universitario Puerta de Hierro de Majadahonda. Spain.
}

\section{BACKGROUND AND GOAL OF STUDY}

Type III Maastricht organ donation after controlled cardiac death (DCD) has became an usual technique in Spain since 2011. Circulatory arrest occurs following limitation of life-sustaining therapy in a controlled ICU or operating room setting in patients with an irreversible and catastrophic illness.

Some studies comparing liver transplantation results between standard brain-death and DCD donors showed no differences in terms of survival while others suggest a higher graft lost and mortality in DCD recipients. None of them assesses transfusion rates.

The goal of this study is to compare transfusion and complications in liver transplantation from standard brain death and DCD donors, considering as well the differences between ECMO and Fast Extraction Technique (FET) in Type III Maastricht.

\section{MATERIAL AND METHODS}

We retrospectively studied 67 patients who underwent liver transplantation between 2013 and 2017 in Puerta de Hierro Hospital, all of them identified from the database of the National Transplantation Organization (ONT). We considered transfusion rates, complications and one year mortality in the 3 groups. Statistical analysis was permormed using SPSS.

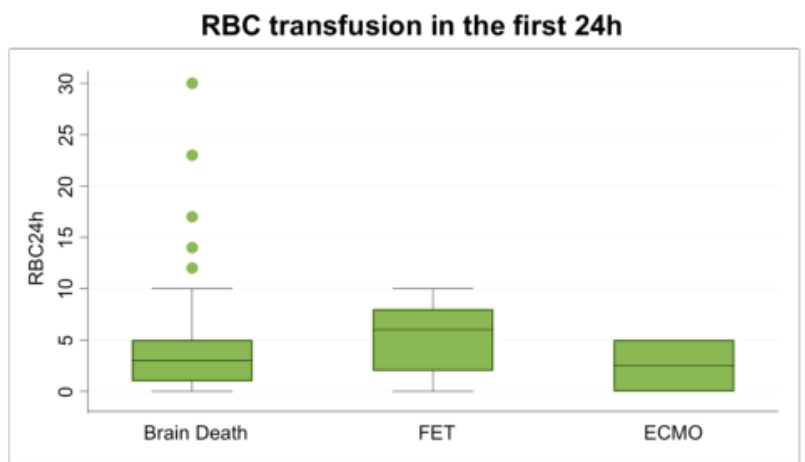

\section{RESULTS AND DISCUSSION}

There were higher rates of biliary complications [IC 95\%; $73 \%(46-84)$ vs $30 \%(18-39) \quad \mathrm{p}<0,038]$ and primary graft dysfunction [IC 95\%; 45\% (19-56) vs $14 \%(3-16) \mathrm{p}<0,031$ ] in Fast Extraction Technique versus the other subgroups. Although ECMO-assisted liver donations after DCD were associated with a decrease in RBC transfusion in the first 24 hours, there was no statistically difference.

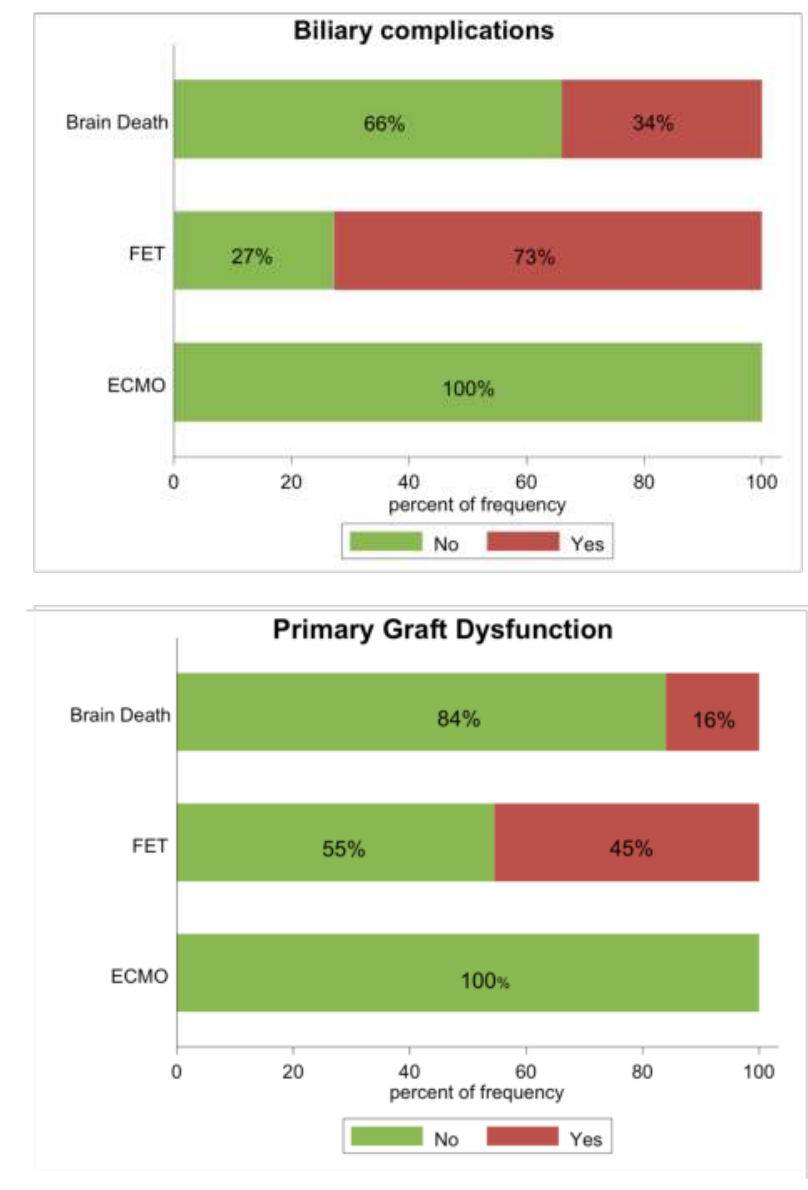

\section{CONCLUSION}

Fast Extracción Tecnique (FET) is asociatiated with lower graft survival. There were no differences in liver transplantation $\mathrm{RBC}$ transfusion rates among groups. 